\title{
Narrativas de resistencia en "La Emancipada" de Miguel Riofrío: análisis literario desde la Teoría Crítica
}

\section{Resistance narratives in "La Emancipada" by Miguel Riofrío: literary analysis from Critical Theory \\ Narrativas de resistência em "La Emancipada", de Miguel Riofrío: análise literária da Teoria Crítica}

\author{
Gabriel Hidalgo Andrade ${ }^{1}$ \\ Universidad de Los Hemisferios \\ gahidalgoa@gmail.com
}

Fecha de recepción:14 de agosto de 2019

Fecha de recepción evaluador: 14 de septiembre de 2019

Fecha de recepción corrección: 15 de octubre de 2019

\begin{abstract}
Resumen
La Emancipada es la primera novela ecuatoriana y una de las primeras latinoamericanas en el subgénero del realismo literario, sin embargo, pasa desapercibida para el debate universitario a los dos siglos del natalicio de su autor Miguel Riofrío. Por el aporte de

\footnotetext{
${ }^{1}$ Constitucionalista y politólogo. Maestrías de investigación en la Universidad Andina Simón Bolívar y en la Facultad Latinoamericana de Ciencias Sociales. Estudios de especialidad en comunicación política en la Universidad Complutense de Madrid y de maestría en Derechos Humanos en la Universidad de Los Hemisferios. Estudios doctorales en el Área de Ciencia Política y de la Administración de la Universidad de Salamanca. Docente en la Universidad de la Américas y en la Universidad Internacional del Ecuador. Columnista en prensa, analista y asesor político. ORCID: https://orcid.org/0000-0003-2160-3866
} 
esta obra, más de un siglo y medio después, se puede demostrar, desde la teoría crítica a la que precede con mucho, que en ésta se pueden encontrar mayores y mejores vestigios de denuncia por la dignidad de las personas, los derechos humanos y el derecho a la resistencia.

Este trabajo se divide en cinco partes. En la primera se contextualizará la redacción de la obra analizada en su momento histórico y según el entorno social del autor. En la segunda parte se estudiará el entorno discursivo de las ideas en La Emancipada y el pensamiento del autor en el contexto de su narrativa. En la tercera parte se analizará la resistencia y la desobediencia como categorías de estudio en el entorno del proceso social y creativo de la obra. En la cuarta parte de evaluará la influencia de la figura materna de la protagonista de la historia según las categorías anticipadas en el apartado anterior. La última parte está dedicada a establecer conclusiones.

Palabras clave: literatura ecuatoriana, literatura latinoamericana, realismo literario, Miguel Riofrio, teoría crítica, derechos humanos, derecho a la resistencia, análisis literario.

\begin{abstract}
Emancipada is the first Ecuadorian novel and one of the first Latin American in the subgenre of literary realism, however, it goes unnoticed for the university debate two centuries after the birth of its author Miguel Riofrío. By the contribution of this work, more than a century and a half later, it can be demonstrated, from the critical theory to which it precedes by far, that in this one you can find greater and better vestiges of denunciation for the dignity of people, Human rights and the right to resistance.

This work is divided into five parts. In the first one, the writing of the work analyzed in its historical moment and according to the author's social environment will be contextualized. In the second part we will study the discursive environment of ideas in La Emancipada and the author's thinking in the context of his narrative. In the third part, resistance and disobedience will be analyzed as categories of study in the environment of the social and creative process of the work. In the fourth part, he will evaluate the influence of the mother figure of the protagonist of the story according to the categories anticipated in the previous section. The last part is dedicated to establishing conclusions.
\end{abstract}

Keywords: Ecuadorian literature, Latin American literature, literary realism, Miguel Riofrio, critical theory, human rights, right to resistance, literary analysis.

\title{
Resumo
}

Emancipada é o primeiro romance equatoriano e um dos primeiros latino-americanos no subgênero do realismo literário; no entanto, passa despercebido para o debate universitário dois séculos após o nascimento de seu autor Miguel Riofrío. Pela contribuição deste trabalho, mais de um século e meio depois, pode ser demonstrado, a partir da teoria crítica à qual ela precede de longe, que nesta você pode encontrar maiores 
e melhores vestígios de denúncia pela dignidade das pessoas., Direitos humanos e direito à resistência.

Este trabalho está dividido em cinco partes. No primeiro, a redação da obra analisada em seu momento histórico e de acordo com o ambiente social do autor será contextualizada. $\mathrm{Na}$ segunda parte, estudaremos o ambiente discursivo das idéias em La Emancipada e o pensamento do autor no contexto de sua narrativa. Na terceira parte, resistência e desobediência serão analisadas como categorias de estudo no ambiente do processo social e criativo do trabalho. Na quarta parte, ele avaliará a influência da figura mãe do protagonista da história, de acordo com as categorias previstas na seção anterior. A última parte é dedicada ao estabelecimento de conclusões.

Palavras-chave: literatura equatoriana, literatura latino-americana, realismo literário, Miguel Riofrio, teoria crítica, direitos humanos, direito à resistência, análise literária.

\section{Introducción}

En septiembre de 2019 se cumplieron dos siglos del natalicio de Miguel Riofrío, el primer novelista del Ecuador. Columnista, político, abogado, escritor y educador, Riofrío empezó a publicar su primera novela "La Emancipada", a los 44 años y por entregas periódicas desde 1863 impresas en el extinto diario quiteño "La Unión". El trabajo, que ha sido constantemente marginado por escritores y estudiosos, se enmarcar en el género de la novela y retrata la vida de Rosaura, una mujer que es obligada por su padre a casarse con un desconocido del que se rebela poco después. La propuesta de Riofrío es precursora del subgénero de realismo literario datado desde la segunda mitad del s. XIX porque se adelanta tempranamente a romper con el romanticismo que privilegia el abordaje de los sentimientos asociados al amor y al desamor propios de la ilustración, y se propone descarnar la situación de conflicto que vive la protagonista de la obra tras emanciparse del matrimonio y de la sociedad conservadora de la época. El argumento gira en torno este rompimiento ideológico, dialógico, narrativo $y$ circunstancial con el pensamiento posromántico. La Emancipada es ambientada en la Loja antigua de mediados del s. XIX, una ciudad situada a $675 \mathrm{~km}$ al sur de Quito la capital del Ecuador, en Sudamérica, urbe desde antaño universitaria, teologal y conservadora, pero castigada por la distancia, el abandono y el centralismo político. La novela explora valores liberales inspirados en el republicanismo y en el anticlericalismo abordando el debate sobre los derechos de las mujeres y de los pueblos indígenas anticipándose a la Revolución Liberal iniciada en 1895, tres décadas después de que se publicara la novela de Riofrío.

Se demostrará desde la teoría crítica, que se pueden encontrar mayores y mejores vestigios de denuncia por la dignidad de las personas en la literatura realista y posromántica que en muchos trabajos militantes y que éstos primeros se anticiparon a abogar por los derechos humanos de las mujeres y de los indígenas desde la inspiración liberal. 
Este trabajo se divide en cinco partes. En la primera se contextualizará la redacción de la obra analizada en su momento histórico y según el entorno social del autor. En la segunda parte se estudiará el entorno discursivo de las ideas en La Emancipada y el pensamiento del autor en el contexto de su narrativa. En la tercera parte se analizará la resistencia y la desobediencia como categorías de estudio en el entorno del proceso social y creativo de la obra. En la cuarta parte de evaluará la influencia de la figura materna de la protagonista de la historia según las categorías anticipadas en el apartado anterior. La última parte está dedicada a establecer conclusiones.

\section{Breve análisis sociocrítico de la procedencia del autor}

Miguel Riofrío Sánchez, hijo del matrimonio integrado por Agustín Riofrío y Valdivieso y por Agueda Custodia Sánchez, nació en Loja el 7 de septiembre de 1822, a menos de tres meses de la Batalla de Pichincha, ${ }^{\mathrm{i}}$ en medio de una familia de clase media alta, propietaria de almacenes de comercio en Loja en Ecuador y en Piura en Perú, Sudamérica (Aguirre, 2005, p. 17). Riofrío concluyó su formación primaria y secundaria en el Colegio San Bernardo de Loja, para luego avanzar en su formación en Leyes en el Convictorio San Fernando de la ciudad de Quito en 1845, recibiéndose como abogado un año después en la luego se llamaría Universidad Central del Ecuador. Fue compañero de Gabriel García Moreno, después convertido en presidente la República en tres distintos periodos entre 1960 y 1975.

En 1863 Miguel Riofrío publica la novela "La Emancipada", en un ambiente de manumisión de la esclavitud dado por la entrada en vigor, en ese mismo año, en los Estados Unidos de Norte América del Acta de Emancipación para los esclavos del Sur, además de la abolición de la esclavitud en Ecuador en el año de 1850, seguida por Venezuela y Perú en 1854. La novela escrita por Riofrio, se escribe en una época en la que el liberalismo y el ideal de democracia estuvieron opacados un conservadurismo intolerante, intransigente y el autoritario (Moscoso, 2006, p. 429).

En 1849, Riofrío Sánchez, se convierte en defensor del posterior gobierno ecuatoriano del presidente Vicente Ramón Roca, quien sería uno de los líderes de la Revolución de Marzo de 1845 en contra la omnipotencia del presidente Juan José Flores (Aguirre, 2005, p. 19). Con esta revolución comenzó en Ecuador un período nacionalista que duró hasta la crisis de 1858 a 1860, momento en el que el Ecuador se dividiría en cuatro gobiernos diferentes. ${ }^{\text {ii }}$ Ramón Roca, al igual que Riofrío, sería partidario de Simón Bolívar, el Libertador de América, en oposición del presidente Manuel Ascazubi Matheu, conservador, contrario al proyecto de las independencias latinoamericanas, lo que le significó a Riofrío Sánchez ocultarse de la persecución política de este primer mandatario (Aguirre, 2005, p. 19).

"La Emancipada" es una novela de ambiente republicano independentista a tono con el resto de las novelas hispanoamericanas emergidas en esta misma circunstancia, además del posromanticismo, costumbrismo y matiz acusatorio (Sacoto, 1983, p. 7-8). El 
relato se desarrolla en torno al año 1842 en el influyente ambiente político de la disolución de la Confederación Peruano-boliviana, además de la Guerra entre esta unión de nación con el Ejército Restaurador Chileno-peruano, del 6 de enero de ese año (Aljovín de Losada, 2001, pp. 65-79).

Es así como el pensamiento político del joven abogado y periodista emerge en un contexto de protestas, resistencia y libertad política, en una accidentada realidad que desvela el conocimiento de las imágenes y roles de las mujeres y los hombres de esa época, a través en cuales se muestra analógicamente la construcción de estas sociedades bajo el espectro del ideal republicano, en un momento de cimentación del naciente estadonación de inspiración franco-americano, y que se recrea en una narrativa que busca organizar el imaginario nacional de la cultura y la sociedad, en donde el intelectual debe intentar la integración de ciudadanos homogéneos en un discurso ficcional (Moscoso, 2006, p. 429; Andrade, 2007, p. 36)

\section{Descripción del pensamiento del autor en el contexto de la narrativa}

Riofrío Sánchez tiene una fuerte influencia de los valores liberales de la época y del independentismo de Bolívar, además de otros principios paralelos que veremos enseguida. Recuérdese que, en la circunstancia de la edad moderna, los valores de la razón ilustrada y la creciente emergencia de la edad contemporánea, se crea y recrea esta novela, con las pasionales ideas de libertad de la Revolución Francesa y la sustitución del hombre ilustrado que desplazaba y reemplazaba al hombre del antiguo régimen del s. XIX, además de la noción occidentalista eurocéntrica del quiebre de estas dos épocas (Carriendo, 2007).

En un tiempo de marcada dicotomía entre el ser europeo, blanco, racional e ilustrado comparado con el "buen salvaje" rousseauniano "transita la novelística ecuatoriana de fines del siglo XIX y principios del XX [como descubrimiento] de relatos novelescos que limitan el papel ficcional de la mujer a modelos que van desde la santidad hasta la prostitución" (Andrade, 2007, p. 37).

Así se presenta Riofrío, describiendo todo lo cotidiano, citadino y típico; prefiere como personajes a Rosaura y Don Pedro, su padre, dos protagonistas dentro de una sociedad conservadora y tradicionalista, acompañados por Eduardo, don Anselmo y el cura de la parroquia, eligiéndolos a éstos de los personajes extravagantes o insólitos de la anterior corriente del romanticismo. E inclusive, la condición de "realista" y narrador de Riofrío se explican en la referencia que haría Manuel J. Calle al calificarlo como "buen escritor, pero pésimo poeta", para describirlo, tal vez, como relator objetivo y menos versista romántico (Aguirre, 2005, p. 28).

Rosaura, siendo despojada por su padre de todos sus libros, papel, pizarra, plumas, vihuela y pinceles, es exigida a abandonar la educación que estaba recibiendo de su madre 
instruida en los valores liberales, e inclusive su madre es acusada de ser librepensadora porque

ella en vez de hilar y cocinar, que es lo que deben saber las mujeres, le gustaba preguntar en donde estaba Bolívar, quienes se iban al Congreso, qué decía la Gaceta, y aguardaba como cosa de reliquia esos libros de Telémaco y no sé que otros extravagantes que le había dejado ese fraile [que la educó en estas Ciencias], que ni sé cómo se llamaba: Unos le decían padre normal, otros padre masón y otros padre maestro, llamándola "masoncita remilgada" (Riofrío, 1863 [2005], pp. 62-63).

Esta confesión es realmente interesante en el contexto ideológico de Riofrío Sánchez considerando que el religioso de apellido Mora al que se hace referencia en esta parte de diálogo corresponde el encargo de instituir una Escuela Lancasteriana por orden de Bolívar en Loja, quien además era un reconocido masón (Martínez, 2011). ${ }^{\mathrm{ii}}$

La orden que dio don Pedro era la de formar a Rosaura en el temor a Dios, el sometimiento conyugal y la prohibición de la educación. Le dice:

Rosaura ya tienes doce años cumplidos es necesario que desde hoy en adelante vivas con temor de Dios; es necesario enderezar tu educación, aunque $[\ldots]$ tu madre $[\ldots]$ ha dañado todos los planes que yo tenía para hacerte una buena hija; yo quiero que te eduques para señora y esa formación empezará desde hoy [...] lo que te diga tu padre lo oirás bajando tus ojos y obedecerás sin responderle, sino cuando fueres preguntada (Riofrío, 1863 [2005], p. 57).

Lo dicho se interpreta como las normas sobre las que don Pedro levanta la formación de su hija y que se manifiestan en tres aspectos:

(i) como un trabajo de conversión de Rosaura no sólo a "cosa" vendible solamente sino a "valor de cambio" pues no podría por sí misma ser valor sin ser un objeto de uso pues si es inútil, "entonces también es inútil el trabajo contenido en ella; $[\mathrm{y}]$ este no cuenta como trabajo", y por tanto no constituiría valor si es entregada como está por eso se entiende que don Pedro deba “enderezar su educación” (Riofrío, 1863 [2005], p. 57; Marx y Engels, 1976, p. 49);

(ii) como educación impuesta desde las formas dominantes del entonces naciente Estado moderno, desde las reglas del respeto a la división social del trabajo y en el orden establecido por la dominación de la clase o de los roles del hombre por encima de la mujer, para definir "quién" da las órdenes (Althusser, 2003, p. 118); y,

(iii)el "sometimiento a la ideología dominante" y a la represión en el temor que chantajea desde la simbología religiosa y en el dominio de su práctica como aparato ideológico del Estado. Esto supone dos nuevas variantes: (a) el sistema religioso que obliga a Rosaura a cierto comportamiento con don Anselmo en su potencial vida matrimonial y frente a la sociedad; y, (b) en caso de inobservancia, a aceptar el castigo previsto por las leyes y por tanto perennizar un sistema represivo de dominación en el Estado que funciona 
mediante la violencia del dominante hombre/blanco/acaudalado (Althusser, 2003, pp. 119 y 126).

Seguramente Rosaura hubiera sido forzada con todo un complejo engranaje de dispositivos de violencia (jueces, testigos, policías, políticos) a cumplir con sus obligaciones contractuales o a ir a prisión por su decisión de desobedecer y desafiar al poder institucionalizado, pero aún con todo el mundo en contra, se rebeló y resistió.

\section{Resistencia y desobediencia: grado de integración en el proceso social}

Lo sucesivo en el texto de Riofrío y anterior a la emancipación de Rosaura es decisorio. Don Pedro de Mendoza, padre de Rosaura, arregla con el párroco el matrimonio de la joven con un terrateniente de Quilanga, don Anselmo de Aguirre y Zúñiga. El acuerdo es de intercambio: dar a Rosaura como si fuera un bien, a cambio de algo que la convierte en una transacción material, por reificación de sí misma porque "no se cambia una levita por sí misma", y expresando reconocimiento de su "mismidad" alienada en las frivolidades de una sociedad patrimonialista (Marx y Engels, 1976, p. 50; Álvarez, 2001, pp. 23-43). ${ }^{\text {iv }}$ Esto sucede así porque el padre de Rosaura se reconoce plebeyo y en el arreglo matrimonial se subsanarían los supuestos vicios de su unión con la madre de la joven. El mismo lo explica en los siguientes términos:

y aunque soy tan caballero como los padres de muchas de ellas, no dejan de hacerme algunos melindres, pues hubo mil de habladurías cuando me casé con tu madre, ¡cuánto mejor me hubiera estado casándome con una campesina y trabajadora como yo! (Riofrío, 1863 [2005], p. 63).

Las amistades del enamorado de Rosaura, Eduardo, se enteran del trato matrimonial y asisten al momento mismo del acuerdo. La reflexión de uno de ellos desvela una posición personal de reclamo, como de resistencia, que plantea Riofrío sobre esta errada práctica familiar en una época salpicada por (a) una praxis social aristocrática en la que la mera observación del otro -como objeto y no como persona- se convirtió en un fin en sí mismo, de tal manera que la conciencia de una relación social se extinguiría, además de (b) ser un tiempo gobernado por un sistema de convicciones de negación de ese otro (Honneth, 2007, p. 137).

Para el primer caso Riofrío escribe: “Tú -dice don Pedro a Rosaura- estarás siempre en la recámara y al oír que alguien llega pasarás inmediatamente al cuarto del traspatio; no más paseos ni visitas a nadie ni de nadie. Eduardo no volverá aquí", (Riofrío, 1863 [2005], p. 57). Para el segundo, escribe: "[nosotros] debemos ser sustancialmente distintos de aquellos pueblos, en que la mujer es entregada como mercancía a los caprichos de un dueño, a quien sirve de utilidad o de entretenimiento, más no de esposa" (Riofrío, 1863 [2005], p. 60)

La dominación expresada en el arreglo matrimonial se ve como una suerte de formación social en la que "la condición final de la producción es la reproducción de las 
condiciones de producción", en términos de Althusser, y desde luego en el pensamiento circunstancial del entonces naciente Estado nacional, esto además del hecho de que nuestra implicación y nuestro reconocimiento previos respecto de otras personas son necesariamente "olvidados" cuando tratamos y consideramos a las personas como mercancías (Althusser, 2003: 115; Honneth, 2007, p. 136). Rosaura fue, no solamente reificada y dada en intercambio, sino también despersonalizada. Pero su respuesta como persona no tardaría en llegar en la trama de la novela.

Como era de esperarse, ella se opone al arreglo porque no está conforme a su voluntad, pero su padre la obliga. Su voluntad no es motivo de interés o discusión, y se argumenta la decisión en la "bendición" del sacerdote que oficia la unión viciada por la nulidad. Don Pedro dice: "hago mal en dejar correr las amonestaciones antes de haber pedido el consentimiento de la novia, como si mi hija pudiera dejar de consentir en lo que el padre lo mande"; además se justifica "si lo dispuso el señor cura, bien dispuesto esta" (Riofrío, 1863 [2005], p. 60).

El padre de Rosaura, mirando su rebeldía, en venganza, maltrata con un garrote a uno de los esclavos indios e intenta matar a un pequeño de ellos. Las frases de don Pedro en contra de los indios son: "Sois una raza maldita y vais a ser exterminados, replicó el tirano, dirigiéndose enseguida con el palo levantado a descargarlo sobre la hija del indio que era una creatura de seis años" (Riofrío, 1863 [2005], p. 66).

En esta escena se nota la crueldad muy propia de los abusos de la época, que responde a una "idea de raza" y otra de "autoconciencia europea de la modernidad" negada en el indio, el otro, el salvaje (De la Torre, 1997). Para García Guerra "en la autoconciencia europea de la modernidad, [las] separaciones se articulan, a partir del proceso colonizador, con otra escisión más, la que se da entre lo moderno (mundo occidental europeo) y lo propio del resto de los pueblos y culturas. Este universalismo excluyente perdura, tras la contribución de Hegel en sus Lecciones de filosofía de la historia, en la división del mundo según determinadas diferencias esenciales" (García Guerra, 2007: 217). Esto se confirma en una sociedad estructurada en las diferencias, o como dice Quijano:

la idea de raza es, con toda seguridad, el más eficaz instrumento de dominación social inventado en los últimos 500 años. Producida en el mero comienzo de la formación de América y del capitalismo, en el tránsito del siglo XV al XVI, en las centurias siguientes fue impuesta sobre toda la población del planeta como parte de la dominación colonial de Europa (Quijano, 1999, p. 192)

Pero Rosaura acepta a las imposiciones de su padre, obligada por la apremiante situación. Se opone en principio, pero finalmente sede, negándose a sí misma, y enajenándose en otra, y ahora no es más ella misma, perdiendo su esencia de ser personal, o en términos de Marx:

cuando un persona se opone a sí misma, se le opone otra persona [...]. En general la tesis de que se le ha enajenado al hombre su esencia genérica significa que una persona ha sido enajenada de otra y que cada una de ellas este enajenada de la esencia humana (Marx, 1966, p. 62). 
Antes se dijo que los "aparatos estatales" funcionan mediante la violencia, pues bien los "aparatos ideológicos del Estado" funcionan mediante los sistemas de ideas dominantes. En primera instancia Rosaura es solamente amenazada, pero luego es reprimida y amenazada a cumplir por la fuerza. La escena demuestra lo que entonces sucedía en este tipo de familia y en su trágica circunstancia. Se trataba de suplantar la formación religiosa y familiar con la imposición de un artificioso aparato aparecido en el nuevo vínculo familiar e impuesto a la sombra un matrimonio no consentido y de un esposo-patrón (Althusser, 2003, p. 133). ${ }^{\mathrm{v}}$

\section{La figura materna en Rosaura: resistencia y rebeldía.}

Rosaura se presenta al acto de unión matrimonial. En contra de lo que todos los asistentes creerían ella acepta muy resuelta a tomar como esposo a don Anselmo. En seguida se produce la bendición del cura, pero inmediatamente ella abandona el lugar de la ceremonia; su padre la increpa, y ella responde de la siguiente manera:

Entiendo, señor, que ya no le cumple a Ud. tomarme cuenta de lo que yo haga [...]. Yo tenía que obedecer a Ud. hasta el acto de casarme porque la ley me obliga a ello: me casé, quedé emancipada, soy mujer libre: ahora que don Anselmo se vaya por su camino, pues yo me voy por el mío (Riofrío, 1863 [2005], p. 71).

El primer episodio de rebeldía y resistencia de Rosaura se revela en la siguiente escena. Ella obliga a salir al cura y a los otros asistentes de la iglesia parroquial, incluido su padre, su esposo, y el teniente político como autoridad judicial. El religioso increpa con amenazas a Rosaura. Ella responde:

Señor cura, aquí hay dos balas que irán veloces hasta el tuétano del atrevido que me insulte: quiere descubrir lo que puede hacer el brazo de una hembra como yo resuelta a arrostrar por todo. Una palabra más y volarán los sesos de mis verdugos: quise perdonarlos a nombre de mi madre; pero ya veo que se empeñan en que descargue sobre ellos mi venganza: ¿lo queréis?; pues enviadme a la cárcel (Riofrío, 1863 [2005], p. 73).

La respuesta del cura y el teniente político fue de miedo y estupefacción. Rosaura, "hembra resuelta" a matar por su libertad-objetivamente al cura o al político, y subjetivamente al poder institucionalizado- no sólo responde violentamente al acto de ser privada de su derecho a resistir, a ser libre, a decidir, sino que se rebela, igualmente con fuerza, a la imposición religiosa, social, política (o a los aparatos ideológicos del Estado, diría Altusser) del mismo dominante, de ser objeto de "una ceguera sistemática relacionada con el prejuicio de que sólo las imposiciones económicas pueden conducir en último término a la negación de los rasgos humanos de las personas" para subvertir al sistema desde la clandestinidad (Althusser, 2003, p. 135).

Para sobrevivir y para resistir, Rosaura no tiene más opción que corromperse. ${ }^{\mathrm{vi}}$ Con el acto de aceptación a la ceremonia religiosa cumple con su promesa y con la sociedad. La unión conyugal no era parte del trato, ni de sus deseos. Ella encuentra su libertad para caer en otra esclavitud: la venta de su cuerpo. La joven se cosifica en el comercio carnal, pero no pierde la esperanza de avanzar en su nueva emancipación en 
Eduardo, con su enamorado. Pero él se ordena en el sacerdocio y huye de ella. Rosaura entonces prefiere quitarse la vida. Por esto

... habiendo renunciado de manera absoluta a sí misma, descubre sin embargo, en la disciplina del trabajo servil, el carácter universal de su acción: por encima de su desnuda vida, colocar el valor del reconocimiento y la libertad general. La fuerza de esta verdad de la autoconsciencia desencadena la transformación: así como el amo revelaba que su esencia es lo inverso de aquello que quiere ser, así también el esclavo al realizarse plenamente devendrá también, sin duda, lo contrario de lo que es de un modo inmediato; retornará a sí y se convertirá en verdadera independencia (López Álvarez, 2001, p. 27).

Andrade afirma que "estas desviaciones se vuelven motivos literarios que se repiten consistentemente, con ejemplos que van desde la hija o esposa desobediente, y que pasan por la mujer pervertida (...) o la que elige un camino distinto al del matrimonio" (Andrade, 2007, p. 36). La categorización de la lectura propuesta por Fausto Aguirre es más franca pues "al analizar la obra supone la relación circular: obra, autor, medio", y la Emancipada no hace más que referir a un punto de vista antropológico desde la visión de la literatura y su creador como reflejo temporal o perenne de las manifestaciones de la cultura; este punto de vista revive las formas de vida, y consecuencias de ella en una sociedad que aun vive alienada, más aun si la penetrante condición psicológica del personaje femenino que constituye un adelanto dentro del contexto literario latinoamericano (Aguirre, 2005, p. 34, 36 y 39).

Además, hace una diferenciación importante. Debe notarse que el padre de Rosaura, al ofrecerla en matrimonio la reifica en mercancía llevándola a una relación despersonalizada en la que ella es entendida como objeto de una transacción mientras el otro, don Anselmo, debe permanecer como portador de cualidades personales generales para poder ser aceptado como persona responsable del intercambio, en tanto que Rosaura niegue su propia humanidad (Honneth, 2007, p. 132). Ella, vista como objeto de intercambio, es enajenada de sí misma y entregada a fuerza a un trabajo conyugal de permanente mortificación (Marx, 1966: 59). Es el equivalente de su decisión de prostituirse después de revelarse, pues se hace presa del comercio de su cuerpo después de que su propio padre la vendiera, y ella lo hace consigo misma para sobrevivir, pero también en acto liberatorio que en sí mismo no es tal, poniéndose en su contra enajenada en otra persona que no es ella. ${ }^{\text {vii }}$

Pero aun así Rosaura reivindica su posición de mujer emancipada, libre. En las actuales circunstancias, Rosaura, no se hubiera prostituido. Su posición de rebeldía al estatus de su época la empujo al papel de la prostituta, adecuado como figura literaria para denunciar la hipocresía de la parte de la sociedad a la que pertenecía y que le negó su identidad particular de mujer, de ciudadana (Zizek, 1998, p. 139).

Rosaura resiste desde la esclavitud de una vida de sistemática exclusión en la prostitución. Lo suyo es un acto de resistencia inmanente al poder como fuerza de contrapoder pues "el Poder mismo genera el exceso de resistencia que finalmente no podrá dominar" (Zizek, 1998, p. 149). Menos de un siglo después Matilde Hidalgo Navarro se convirtió en la primera mujer ecuatoriana en licenciarse en medicina en 1919 
y doctorarse como médica en 1921 en Ecuador y en ser la primera mujer en ejercer formalmente el derecho al sufragio en toda Latinoamérica en 1924. Por esta rebeldía en contra del estatus social, Matilde, católica practicante, fue excomulgada.

\section{Conclusiones. Resistencia en La Emancipada como sistema de representaciones}

La ideología que nos muestra Miguel Riofrío en La Emancipada tiene dos dimensiones: (a) la suya propia, de resistencia y protesta al sistema jurídico religioso de exclusión y dominación en la sociedad; y (b) la ideología como el sistema de ideas, de representaciones, que domina el espíritu de un hombre o un grupo social, quien le da legitimidad y vigencia, a través de la obediencia y "temor" al sistema jurídico vigente en representaciones ciertas representaciones religiosas.

En la correspondencia mantenida entre Eduardo y Rosaura antes de morir, ella le espeta duramente los argumentos en contra de su cobardía: formas y formalismos sociales. Él le responde desde la comodidad y seguridad del poder institucionalizado, adoptando una postura de falsa sobriedad.

Rosaura resistió desde la auto reificación. Después de aceptar la unión matrimonial se emancipó y se dio la libertad a sí misma, violentamente y bajo amenazas. Luego, por su voluntad se prostituyó por un asunto de supervivencia obviamente, pero además para contestar desde este oficio a una sociedad prejuiciada y melindrosa.

El orden jurídico de la época garantiza las relaciones de dominio y también ahora. En la novela leída, Rosaura le debía obediencia hasta el matrimonio a su padre, y por causa de su unión conyugal ella pasa a subordinarse a otro hombre, su marido. Ella resiste, protesta y subvierte el orden impuesto por este aparato ideológico del que se sirve el Estado para segmentar y distribuir el poder en función de criterios de género y patrimonio.

Tras leer la Emancipada, urge reponer a Miguel Riofrío, como a los autores realistas, a las aulas universitarias como evidencia de lo que podría debatirse a favor del derecho, la ciencia política y las ciencias sociales, desde una perspectiva liberal.

\section{Bibliografía}

Aguirre, F. (2005). "Presentación", en Riofrío, M. La Emancipada, Loja: Editorial de la Universidad Técnica Particular de Loja.

Aljovín de Losada, C. (2001). "La Confederación Perú-Boliviana 1836-1839: Política interna o externa", Investigaciones Sociales, 5 (8).

Althusser, L. (2003). “Ideología y Aparatos Ideológicos del Estado", en Zizek, S. (comp.), Ideología: Un mapa de la cuestión, Buenos Aires: Fondo de Cultura Económica. 
Andrade, JO. (2007). "Entre la santidad y la prostitución: la mujer en la novela ecuatoriana en el cruce de los siglos XIX y XX", Iconos, Revista de Ciencias Sociales, 28.

Carriendo Castro, P. (2007). Consideraciones en torno al marxismo, la literatura y el problema del realismo social. Nómadas. Critical Journal of Social and Juridical Sciences, 15(1).

Colombani, MC. (2008). “A propósito de Dioniso y Apolo. Mismidad y Otredad: el juego de las tensiones", Nuntius Antiquus, 2.

De la Torre, C. (1997). "La letra con sangre entra": racismo, escuela y vida cotidiana en Ecuador", trabajo presentado en el Latin American Studies Association, Conference, Guadalajara 19 de abril.

García Guerra, M. (2007). "La razón mestiza: agenda intercultural”, Colección Estudios Creade, 2.

Honneth, A. (2007). Reificación: Un estudio en la teoría del reconocimiento, Buenos Aires: Latingráfica SRL.

López Álvarez, P. (2001). "El sujeto impropio: identidad, reconocimiento y autonomía", Logos: Anales del Seminario de Metafísica, 34.

Martínez Esquivel, R. (2011). El fantasma de Bolívar en la masonería venezolana de Eloy Enrique Reverón García. REHMLAC. Revista de Estudios Históricos de la Masonería Latinoamericana y Caribeña, 3(1), 209-218.

Marx, K. (1996). Manuscritos económicos-filosóficos de 1844, en Escritos económicos varios, Moscú: Progreso.

Marx, K. y Engels, F. (1976). Obras, vol. 40, Barcelona: Editorial Grijalbo.

Mora García, JP. (2005). "La institución escolar en los cantones de La Grita y San Cristóbal, en el tiempo histórico de la Gran Colombia, (1821-1830)", Aldea Mundo, 7(13).

Moscoso, M. (2006). "Imágenes y roles de género en "La Emancipada”. Primera novela ecuatoriana, 1863”, en O'Phelan Godoy, S; Zegarra, M. \& Gil, RA (editoras), Mujeres, Familia y Sociedad en la Historia de América Latina, Siglos XVIII-XXI, Lima: Instituto Riva-Agüero No 229.

Quijano, A. (2004). "Colonialidad del Poder, eurocentrismo y América Latina", en Pajuelo, R. y Sandoval, S. (compiladores), "Globalización y diversidad cultural", Lima: Instituto de Estudios Peruanos.

Quijano, A. (1999). “iQué tal raza!”, en Familia y cambio social, Lima: CECOSAM. 
Sacoto, A. (1983). “Introducción”, Riofrío, M. La Emancipada, Cuenca: Departamento de difusión cultural de la Universidad de Cuenca.

Riofrío, M. (2005). La Emancipada, Loja: Editorial de la Universidad Técnica Particular de Loja.

Zizek, S. (1998). "Multiculturalismo o la lógica cultural del capitalismo multinacional", en Estudios Culturales. Reflexiones sobre el multiculturalismo, Buenos Aires: Editorial Paidós.

\section{Notas}

${ }^{\text {i }}$ La Batalla de Pichincha se refiere al enfrentamiento bélico ocurrido en el contexto de las guerras de independencia hispanoamericana y que asegurara la independencia administrativa de las provincias que pertenecían a la Real Audiencia de Quito. De esta manera, Riofrío nació y creció en el contexto de la emergencia de las incipientes republicas presidencialistas latinoamericanas.

ii De esta forma se puede creer que Riofrío Sánchez viviría de cerca el proceso de Constitución Federal del Estado de Loja, y por tanto estas incidencias serían determinantes en la inclinación de sus ideas liberales.

iii En 1798, Joseph Lancaster un cuáquero inglés y reformista de la educación pública, fundó una escuela primaria en Borough Road, Southwark, utilizando una variante del sistema de enseñanza mutua fundado por Andrew Bell. Sus ideas fueron desarrolladas en forma simultánea con las Bell en Madras, cuyo sistema fue referido como "el sistema educativo de Madras". El método de instrucción y entrega es recursivo, ya que si uno de los estudiantes aprende el material es recompensado por haberle pasado exitosamente la información a otro alumno. Este método se conoce actualmente como un "tutor al mismo nivel". En época de la Gran Colombia, el 26 de enero de 1822, Francisco de Paula Santander, decretó las Escuelas Normales por el Método Lancasteriano en Bogotá, Caracas, y Quito con ayuda de sacerdotes jesuitas (Mora García, 2005: 80).

iv "La Mismidad, como eje de poder, consolida la construcción y conservación de la tradición y la transmisión de la memoria tanto individual como colectiva, y constituye el paradigma de las formas en que se expresa o se nos atribuyen las notas de una determinada identidad.- La Otredad, en cambio, dibuja un escenario complejo; su territorio incluye los modos de entrar en relación, visualizar, calificar o descalificar a los otros hombres que difieren en sus aspectos físicos exteriores, en sus costumbres y en algunas formas de construir sus identidades" (la itálica es mía), (Colombani, 2008, pp. 26 y 27)

${ }^{v}$ Extraordinarios parecidos relacionan a Rosaura con Matilde Hidalgo Navarro, primera mujer ecuatoriana en ejercer formalmente el derecho al voto político en Latinoamérica y primera mujer ecuatoriana en cursar una carrera universitaria que fuera excomulgada tras saberse su decisión de estudiar la carrera de Medicina en la Universidad de Cuenca.

${ }^{\mathrm{vi}}$ Rosaura prefiere la prostitución y opta por esto para sobrevivir en lugar del oprobio del sometimiento. En la segunda carta dirigida Eduardo, su enamorado de la juventud, Rosaura le dice que ha visto a sus "plantas sotanas y cerquillos, y he tenido al capricho de enardecer los galanes del orden sacerdotal, para luego expelerles con desprecio. Ellos se han vengado subiendo a retratarme en el púlpito con groseros coloridos, sin perjuicio de volver a pedir de rodillas perdón” (Riofrío, 1863 [2005], p. 82)

vii "Es cierto que el comer, beber, el acto sexual, etc., son también funciones verdaderamente humanas. Pero, en la abstracción que las separa del círculo de toda la actividad restante del hombre y las convierte en metas últimas y únicas, revisten carácter animal" (Marx, 1966: 59). "Cuando una persona se opone a sí misma, se le opone otra persona. (...) En general, la tesis de que se le ha enajenado al hombre su esencia genérica significa que una persona ha sido enajenada de otra y que cada una de ellas esta enajenada de la esencia humana" (Marx, 1966, p. 62). 